\title{
Volunteer Group
}

National Cancer Institute

\section{Source}

National Cancer Institute. Volunteer Group. NCI Thesaurus. Code C19440.

A group of individuals who voluntarily enter into an agreement to form a body (or organization) to accomplish a purpose. 